\title{
Cerebral toxoplasmosis in HIV-infected patients over 2015-2018 (a case study of Russia)
}

\author{
O. V. Azovtseva ${ }^{1}$ (D) E. A. Viktorova ${ }^{2}$, E. G. Bakulina ${ }^{3}$, A. S. Shelomov ${ }^{4}$ and \\ T. N. Trofimova 4
}

\section{Original Paper}

Cite this article: Azovtseva OV, Viktorova EA, Bakulina EG, Shelomov AS, Trofimova TN (2020). Cerebral toxoplasmosis in HIV-infected patients over 2015-2018 (a case study of Russia). Epidemiology and Infection 148, e142, 1-6. https://doi.org/10.1017/ S0950268820000928

Received: 22 January 2020

Revised: 22 April 2020

Accepted: 29 April 2020

\section{Key words:}

Cerebral toxoplasmosis; clinical picture; HIV infection; medical imaging; pathoanatomy

Author for correspondence:

O. V. Azovtseva,

E-mail: azovtsevaol@rambler.ru (c) The Author(s), 2020. Published by Cambridge University Press. This is an Open Access article, distributed under the terms of the Creative Commons AttributionNonCommercial-NoDerivatives licence (http:// creativecommons.org/licenses/by-nc-nd/4.0/), which permits non-commercial re-use, distribution, and reproduction in any medium, provided the original work is unaltered and is properly cited. The written permission of Cambridge University Press must be obtained for commercial re-use or in order to create a derivative work.

\section{CAMBRIDGE UNIVERSITY PRESS}

${ }^{1}$ Yaroslav-the-Wise Novgorod State University, Veliky Novgorod, Russia; ${ }^{2}$ Central City Clinical Hospital, Veliky Novgorod, Russia; ${ }^{3}$ N. P. Bekhtereva Institute of Human Brain of Russian Academy of Sciences, St. Petersburg, Russia and ${ }^{4}$ I. P. Pavlov First St. Petersburg State Medical University, St. Petersburg, Russia

\begin{abstract}
Cerebral toxoplasmosis is a leading cause of the central nervous system disorders in acquired immune deficiency syndrome. This study aimed to investigate the clinical course of cerebral toxoplasmosis in human immunodeficiency virus (HIV)-infected individuals. The study included $90 \mathrm{HIV}$-infected patients with cerebral toxoplasmosis, who underwent inpatient treatment. In case of positive enzyme immunoassay, HIV infection was confirmed with the immunoblot test. The HIV-1 ribonucleic acid level was determined using the polymerase chain reaction method. The flow cytometry was used for counting CD4 (cluster of differentiation 4 cells). Pathomorphological examination included the autopsy, gross and microscopic examination of internal organs, histological and other methods. The incidence of cerebral toxoplasmosis significantly increases at the CD4 count below 100 cells $/ \mu \mathrm{l}, P<0.001$, and at the HIV viral load above 50 copies $/ \mathrm{ml}, P<0.05$. The clinical picture of cerebral toxoplasmosis included focal symptoms, cognitive impairment, toxic syndrome, mild cerebral symptoms and a meningeal symptom. Given the absence of a specific clinical picture and the absence of abnormal laboratory and instrumental findings, the cerebral toxoplasmosis needs to be diagnosed with a number diagnostic methods combined: clinical examination, laboratory testing, immunological examination, molecular genetic testing and neuroradiological imaging.
\end{abstract}

\section{Introduction}

The human immunodeficiency virus (HIV) epidemic of today is characterised by the presence of many severe cases [1], frequently involving the brain [2-4]. Cerebral toxoplasmosis is a leading cause of the central nervous system disorders in acquired immune deficiency syndrome (AIDS). It is a severe disease, which occupies a third place among fatal diseases [5]. The causative agent of cerebral toxoplasmosis is Toxoplasma gondii, an opportunistic intracellular parasite that can infect and destroy any nuclear cells.

The prevalence of toxoplasmosis is around $25-30 \%$ of the world's human population $[6,7]$, significantly varying between regions (from $10 \%$ to $80 \%$ ), within the country and within different ethnic and social groups [7-9]. The highest infection rates are reported in South America (42-72\%) and Asia (40\%) [10].

The development of brain T. gondii in the late stages of HIV infection is overwhelmingly associated with the reactivation of latent infection due to strong immunosuppression [5]. In the later stages, Toxoplasma can disseminate causing damage not only to the brain but also to the lungs, eyes, lymph nodes and to the gastrointestinal tract [11].

The laboratory diagnosis of cerebral toxoplasmosis is fraught with difficulties. First: the production of specific antibodies, especially immunoglobulin $\mathrm{M}(\operatorname{IgM})$, is low. Second, the polymerase chain reaction (PCR) assay is not sensitive enough, ranging from $35 \%$ to $83 \%$ according to different authors $[12,13]$.

In the absence of immunoglobulin G (IgG), antibodies can be found. High IgG titres (64 and higher in indirect fluorescent antibody test; 6400 and higher in enzyme-linked immunosorbent assay (ELISA)) indicate the phase of reactivation of the latent infection but a low level of IgG does not exclude the development of cerebral toxoplasmosis [14]. Some authors recommend determining the presence of specific antibodies not only in the blood but also in the cerebrospinal fluid (CSF) [15]. The presence of IgG in the CSF is considered a reliable criterion for the reactivation of the infection [15]. Other authors argue that a combined seropositivity of plasma and CSF occurs only in $62 \%$ of cases [16] and is more likely in the presence of high serum titres [15]. Another effective criterion for the reactivation of Toxoplasma infection is the presence of immunoglobulin A T. gondii antibodies in the blood, as their count correlates with the invasion process [17].

Brain magnetic resonance imaging (MRI) is the main instrumental method for the diagnosis of cerebral toxoplasmosis but the MRI findings that are present in the literature are contradictory. 


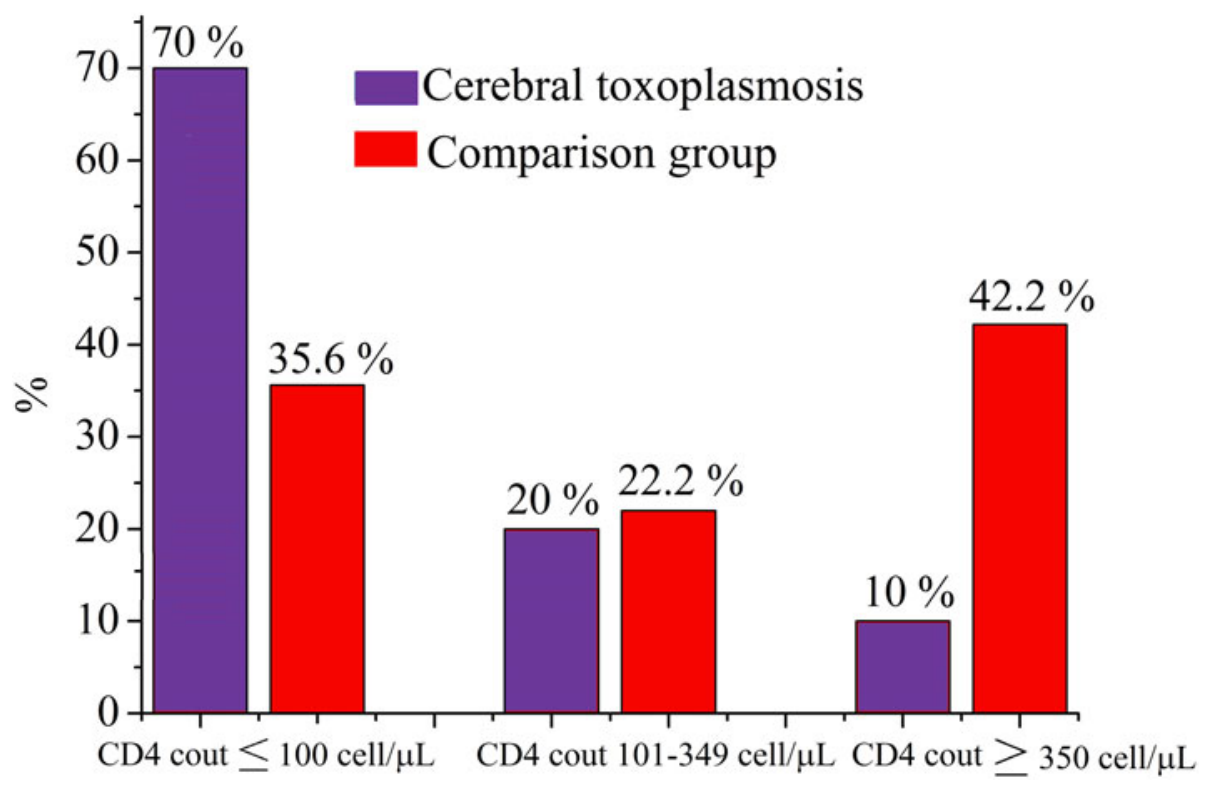

Fig. 1. Frequency of cerebral toxoplasmosis in terms of CD4 lymphocyte count, $n=90$.

Many authors agree only with the fact that etiotropic therapy causes the reduction of abnormalities on the MRI in patients with cerebral toxoplasmosis within 2 weeks of application [18-20].

The pathomorphological interpretation of brain lesions in HIV-infected is difficult to accomplish because structural changes that occur in the brain in some opportunistic diseases remain poorly understood [21].

The study aimed to collect clinical, radiological and morphological data on HIV-infected patients with cerebral toxoplasmosis.

\section{Methods}

\section{Ethical approval}

The study was conducted under the ethical guidelines for retrospective studies and does not disclose data on individual patients.

\section{Participants}

The study included $90 \mathrm{HIV}$-infected patients with cerebral toxoplasmosis. Of these, 73 patients underwent treatment at the Botkin Infectious Disease Hospital and the Center for the Prevention and Control of AIDS and Infectious Diseases in St. Petersburg during 2015-2018. Seventeen patients underwent inpatient treatment at the Novgorod Infectious Diseases Hospital, where they later died within the period between 2016 and 2018. The comparison sample consisted of 225 HIV-infected patients with pathologies other than a brain damage from toxoplasmosis and who underwent inpatient treatment during the same observation period. The study groups were comparable with regard to age and sex.

\section{Diagnosis and testing}

In case of positive enzyme immunoassay, HIV infection was confirmed with the immunoblot test. The HIV-1 ribonucleic acid levels were determined using real-time PCR. The flow cytometry was used for counting CD4 cells.

To confirm cerebral toxoplasmosis, laboratory methods and MRI of the brain were used. The laboratory diagnosis was performed by serological detection of T. gondii-specific IgG and IgM antibodies in the blood serum with ELISA; and by molecular detection of T. gondii deoxyribonucleic acid (DNA) in the CSF.

The instrumental methods included brain imaging at 1.5 and 3.0 Tesla. The MRI procedure included T1-weighted (T1-VI) and T2-weighted (T2-VI) sequences, Fluid Attenuation Inversion Recovery (FLAIR), diffusion-weighted imaging (DWI) and T1-weighted spin-echo sequences acquired before and after contrast administration. If necessary, the following procedures were additionally used: diffusion coefficient index (DCI), gradient echo, susceptibility-weighted angiography/susceptibility-weighted imaging (SWI) [22].

Pathomorphological examination included autopsy as well as gross, microscopic and histological examination of internal organs.

The diagnostic criteria for cerebral toxoplasmosis included the presence of cytosis in the CSF (frequency rate, 70\%); high amount of lymphocytes and protein in the CSF (frequency rate, 70\%); the presence of high and medium titres of Toxoplasma IgG antibodies in the serum sample (frequency rate, 100\%); and the presence of T. gondii DNA in the CSF sample (frequency rate, 35.5\%). However, the absence of $T$. gondii DNA did not exclude cerebral toxoplasmosis due to low sensitivity (35\%) of molecular method. The final diagnosis was made taking into account the clinical, laboratory, radiological and morphological findings.

\section{Data analysis}

Statistical data analysis was performed in Statistica v.9 using parametric and non-parametric methods. The quantitative measures included the arithmetic mean and the standard error of mean $(M \pm m)$. All differences were considered significant at $P<0.05$.

\section{Results}

Cerebral toxoplasmosis was the most frequent opportunistic infection with brain damage diagnosed, being detected in 90 patients. Among them, $75.5 \%$ were men and $24.4 \%$ women at the age $37.0 \pm 6.8$. The average duration of disease was $6.7 \pm 5.4$ 


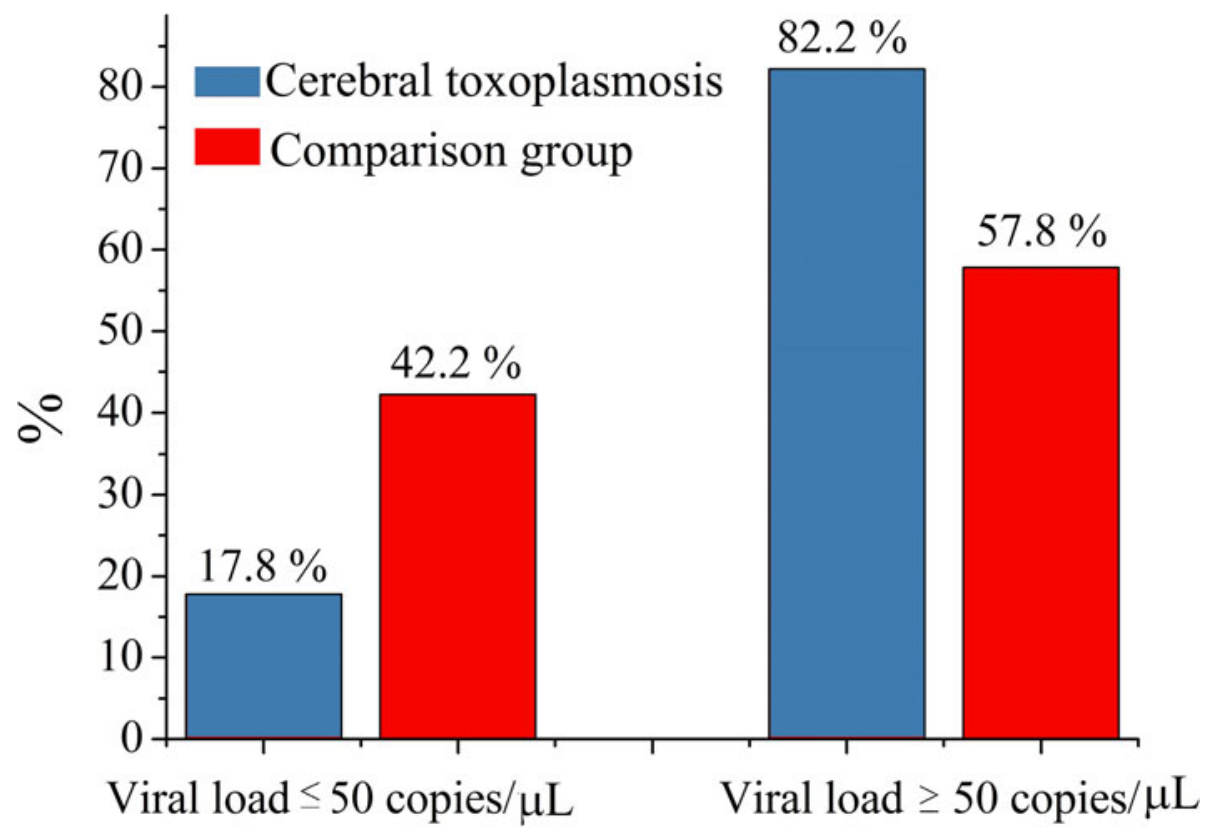

Fig. 2. Frequency of cerebral toxoplasmosis in terms of viremia level, $n=90$.

years. Twenty-five patients (27.7\%) had never received an antiretroviral therapy (ART). The CD4 counts were variable, ranging from 39.6 to 229.6 cells/ $\mu \mathrm{l}$, with a mean of 69.0 cells/ $\mu \mathrm{l}$. The mean viral load burden was 41.743 copies $/ \mathrm{ml}$.

The frequency of cerebral toxoplasmosis in relation to the degree of immunosuppression, viral load and antiretroviral treatment duration

In the total cohort of HIV-infected, cerebral toxoplasmosis at the CD4 count $\leqslant 100$ cells $/ \mu$ l was more frequent $(P<0.001)$ compared to CD4 count above 101 cells/ $\mu \mathrm{l}$ and above 350 cells/ $\mu$ l (Fig. 1).

Among patients diagnosed with toxoplasmosis, the proportion of individuals with suppressed viral load was lower than of those with a viral load above 50 copies/ $\mu \mathrm{l}(P<0.05)$ (Fig. 2$)$.

With a shorter ART, cerebral toxoplasmosis is more likely to result in a serious brain damage compared to longer treatment (Table 1).

Cerebral toxoplasmosis manifested in the form of Toxoplasma meningoencephalitis and Toxoplasma encephalitis.

The clinical picture of cerebral toxoplasmosis involved focal symptoms (frequency rate, 100\%) such as hemiparesis, aphasia, ataxia, alexia and cranial nerve palsies; and cognitive impairment (frequency rate, 100\%) such as the impaired memory, concentration, and perception, temporal and spatial orientation. Cognitive disorders developed at the onset of toxoplasmosis in some patients and against the background of neurological damage in other patients. Apart from that, there were reports on the toxic syndrome (frequency rate, 100\%), mild cerebral symptoms (frequency rate, $87.8 \%$ ) and the meningeal symptom (frequency rate, $70 \%$ ).

\section{Radiological characteristics of cerebral toxoplasmosis in HIV-infected patients}

The presence of multiple, less often single, lesions on MRI, with ring and/or nodular enhancement on contrast. Lesions were found in the basal ganglia, thalamus and at the cortical/white matter border, with perifocal oedema and mass effect (Figs 34). These lesions had high or mixed signal intensity on
Table 1. Frequency of cerebral toxoplasmosis depending on the duration of antiretroviral treatment, $n=90$

\begin{tabular}{lcc}
\hline $\begin{array}{l}\text { Antiretroviral } \\
\text { therapy duration }\end{array}$ & $\begin{array}{c}\text { Patients with brain } \\
\text { damage due to } \\
\text { cerebral } \\
\text { toxoplasmosis, } n\end{array}$ & $\begin{array}{c}\text { Patients with brain } \\
\text { damage due to } \\
\text { cerebral } \\
\text { toxoplasmosis, (\%) }\end{array}$ \\
\hline $\begin{array}{l}\text { Short-term } \\
\text { treatment, 1 year } \\
\text { and less }\end{array}$ & 43 & 66.2 \\
\hline $\begin{array}{l}\text { Middle-term } \\
\text { treatment, 1-5 } \\
\text { years }\end{array}$ & 19 & $29.2, P<0.05$ \\
\hline $\begin{array}{l}\text { Long-term } \\
\text { treatment, } 5 \\
\text { years }\end{array}$ & 3 & $4.61, P<0.01$ \\
\hline
\end{tabular}

T2-weighted and FLAIR images, and low signal intensity on T1-weighted images. Some abscesses demonstrated the involvement of haemorrhage (Fig. 5). The central diffusion restrictions of the pus abscesses were not observed (Fig. 6).

\section{Morphology of cerebral toxoplasmosis in HIV-infected patients}

Lesions had three distinct zones: a necrotic centre, an intermediate zone with intense inflammatory reaction and a peripheral zone with an encysted form of Toxoplasma. Cerebral toxoplasmosis occupied a leading place among conditions that caused damage to the brain, accounting for $20 \%$ [23].

Gross: single or multiple cream coloured foci of necrosis. Histological examination revealed necrotic changes and a mild exudative reaction. In necrotic masses, the Toxoplasma cysts were found (Fig. 7).

\section{Discussion}

The MRI visualisation of pathological processes that take place in the brain is undoubtedly of great diagnostic value, especially in 

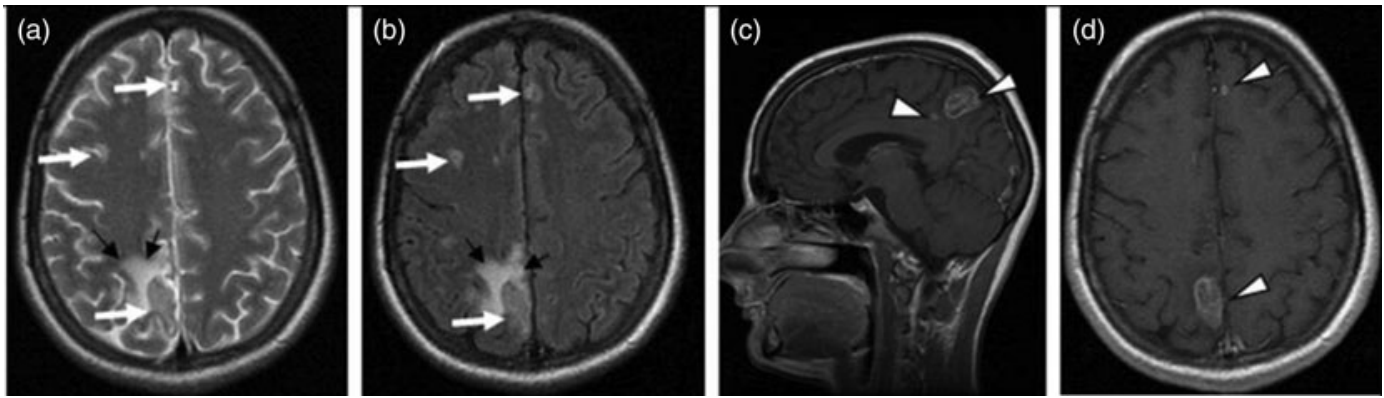

Fig. 3. Cerebral toxoplasmosis. A - T2-VI; B - T2 FLAIR; C, D - T1-VI. Multifocal brain damage (white arrows), with perifocal oedema (black arrows), and a ring accumulation pattern of the contrast agent (arrowheads).
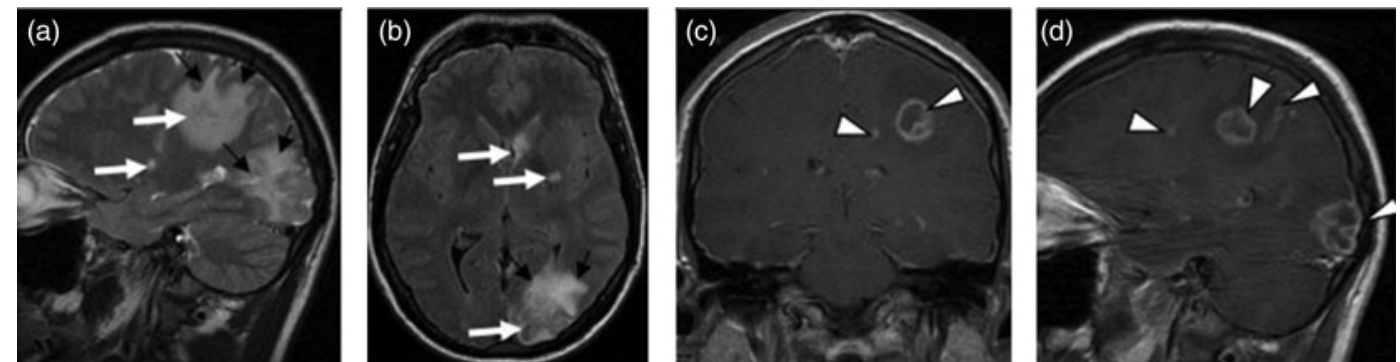

Fig. 4. Cerebral toxoplasmosis. A - T1-VI; B - T2 FLAIR; C, D - T1-VI. Multifocal brain damage (white arrows), with perifocal oedema (black arrows), ring and nodular accumulation patterns of the contrast agent (arrowheads).

Fig. 5. Cerebral toxoplasmosis. A - T2 FLAIR; B - SWI; C - T1-VI. Multifocal brain damage with perifocal oedema (white arrows) and haemoglobin breakdown products (black arrows).
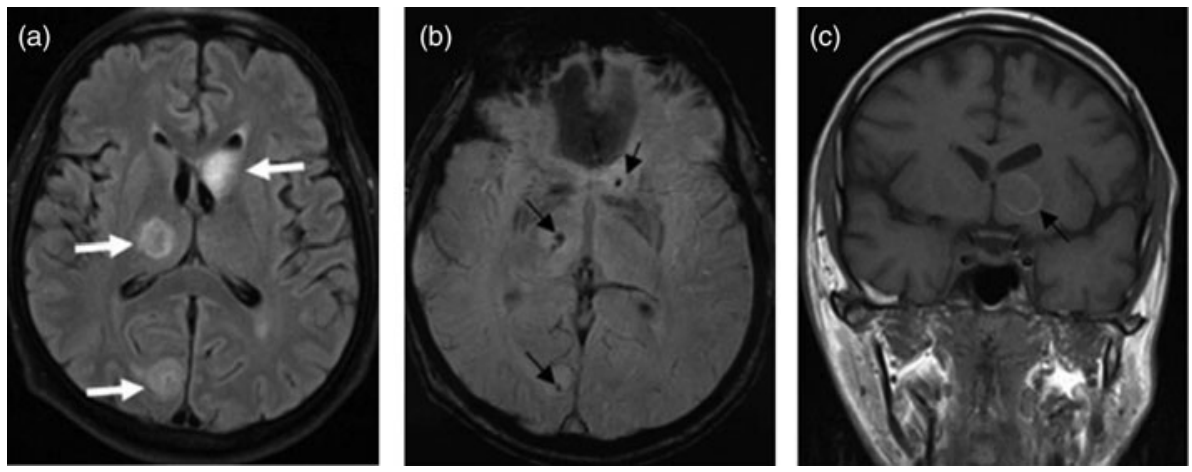

differential diagnosis or when an adequate laboratory testing is not possible or provides uncertain results [24-26]. In cerebral toxoplasmosis, multiple lesions are a common implication. Single foci in the brain were mostly found in patients with acute clinical symptoms. In this case, an oedema surrounding the foci is more observed and, if present, it can contribute to a severe form of toxoplasmosis and a possibly higher mortality.

Dynamic MRI scans are important for monitoring treatment and outcomes. The positive clinical dynamics $[12,15]$ and a decrease in MRI abnormalities within 2 weeks of etiotropic treatment [16] indicate progress in therapy. These tendencies were not observed in patients who eventually died.

Cerebral toxoplasmosis is the most frequent opportunistic infection of the brain among diagnosed. The incidence of cerebral toxoplasmosis significantly increases at the CD4 count below 100 cells $/ \mu \mathrm{l}, P<0.001$, and at the HIV viral load above 50 copies $/ \mathrm{ml}, P$ $<0.05$. However, the identification frequency of cerebral toxoplasmosis reduced significantly among patients who had more than 1 year of ART treatment, $P<0.01$.

The clinical picture of cerebral toxoplasmosis included focal symptoms $(100 \%)$, cognitive impairment $(100 \%)$, toxic syndrome (100\%), mild cerebral symptoms (87.8\%) and a meningeal symptom (70\%). On the contrast-enhanced MRI scans, multiple, less often single, ring- and nodular-enhancing lesions with perifocal oedema and mass effect were observed in the basal ganglia, thalamus, at the cortical/white matter border. The PCR assay revealed $35.5 \%$ of T. gondii DNA in the CSF samples (non-specific criterion).

Therefore, cerebral toxoplasmosis is diagnosed through a combination of diagnostic methods (i.e. clinical examination, laboratory testing, immunological research, molecular genetic testing and neuroradiological imaging).

Cerebral disturbances in HIV-infected patients can be linked to multiple factors. To begin with, the parasite itself is capable of damaging the brain tissue. The time to brain involvement 

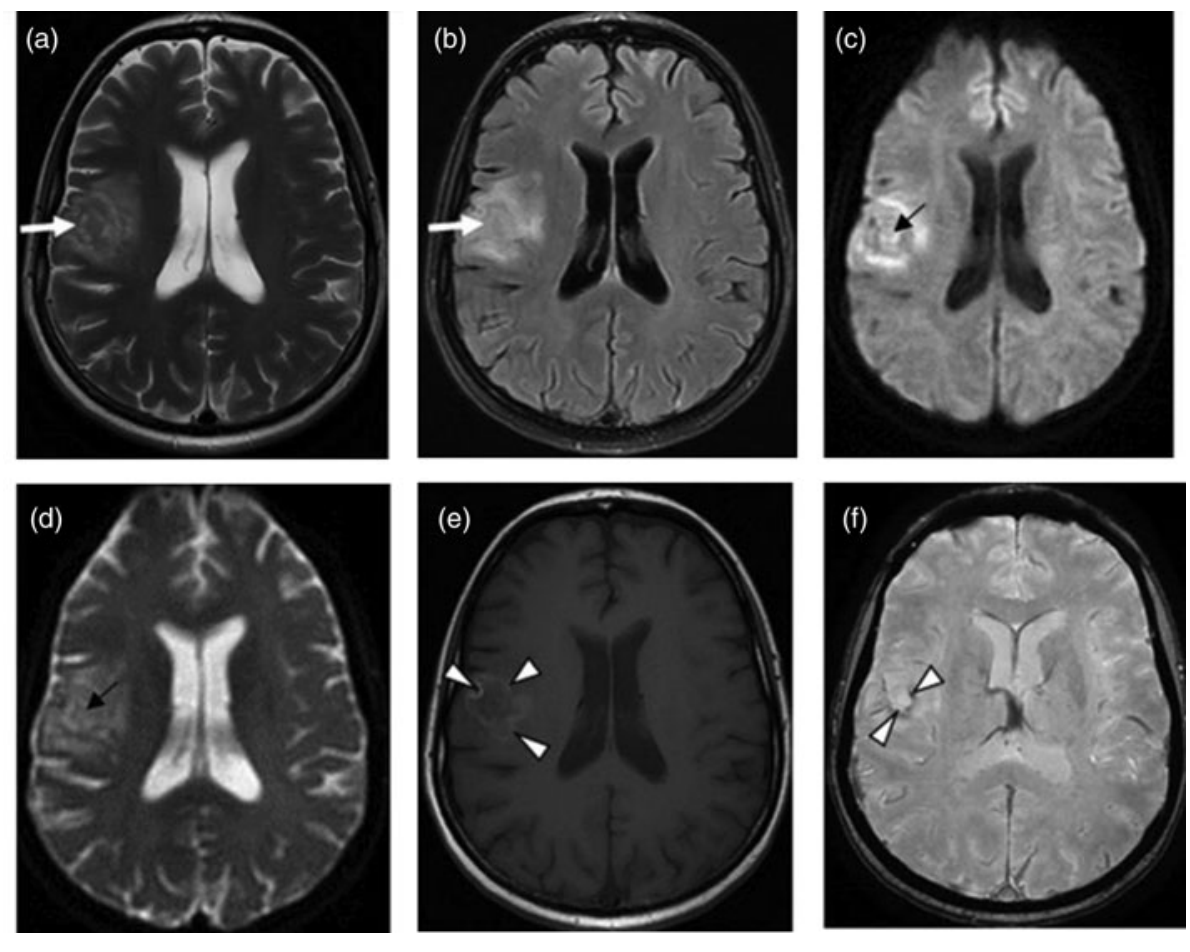

Fig. 6. Cerebral toxoplasmosis. A - T2-VI; B - T2 FLAIR; C - DWI; D - DCl; E - T1-VI; F - SWI. Multifocal brain damage with perifocal oedema (white arrows), with the absence of reduced diffusion in the central part (black arrows), and with the haemoglobin breakdown products (arrowheads).
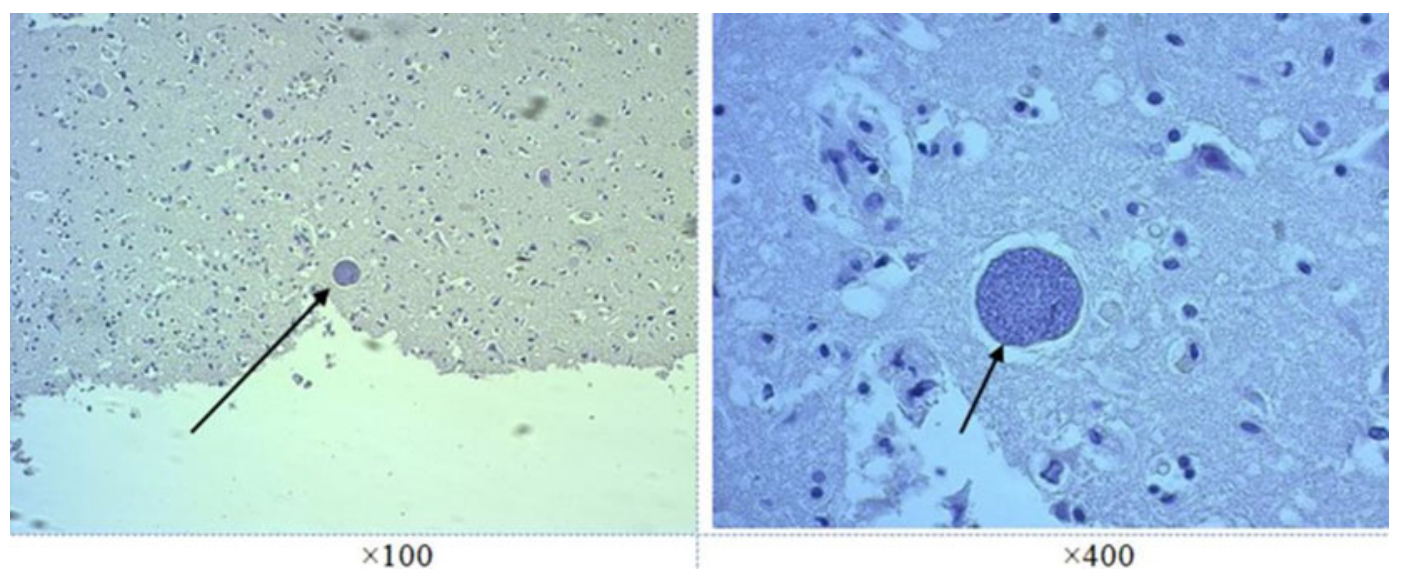

Fig. 7. Cerebral toxoplasmosis, haematoxylin-eosin stained. Spherical cyst (arrows) with multiple Toxoplasma.

largely depends on the strength of the immune system, brain health, drug addiction and alcohol abuse $[25,27]$. The brain damage can be associated with the development of opportunistic infections including cerebral toxoplasmosis and secondary diseases, which can have a diverse range of risk factors.

Presently, MRI is regarded as the major radiological method for examining HIV-infected patients, whereas it poses a challenge even to experienced neuroradiologists [25]. Therefore, the accurate interpretation of cerebral damage requires the combined use of methods such as clinical, laboratory and radiological examinations [25-28].

Financial support. This research received no specific grant from any funding agency, commercial or not-for-profit sectors

Conflict of interest. None.
Ethical standards. This article does not contain any studies with human or animal subjects performed by any of the authors.

\section{References}

1. Belyakov ON and Rassokhin VV (2019) Comorbid Conditions in HIV. Part II: Secondary and Concomitant Infections. St. Petersburg: Baltic Medical Education Center, pp. 252.

2. Shelomov AS et al. (2017) Clinical and radiological characteristics of central nervous system lesions in HIV-infected patients. HIV Infection and Immunosuppression 9, 43-44.

3. Shapshak P, Kangueance $\mathbf{P}$ and Fujimura RK (2011) Neurological manifestations of HIV infection. AIDS (London, England) 1, 3-21.

4. Bicanic T (2009) Immune reconstitution inflammatory syndrome in HIV-associated Cryptococcal meningitis: a prospective study. Journal of Acquired Immune Deficiency Syndromes 51, 130-134. 
5. Goncharov DB, Gubareva EV and Kobets NV (2012) Toxoplasmosis in HIV infection: invasion reactivation criteria. Zhurnal Mikrobiologii, Epidemiologii, i Immunobiologii 4, 88-92.

6. Montoya JG and Liesenfeld O (2004) Toxoplasmosis. Lancet (London, England) 363, 1965-1976.

7. Pappas G, Roussos N and Falagas ME (2009) Toxoplasmosis snapshots: global status of Toxoplasma gondii seroprevalence and implications for pregnancy and congenital toxoplasmosis. International Journal for Parasitology 39, 1385-1394.

8. Dubey JP (2009) Toxoplasmosis of Animals and Humans. Florida: CRC Press, pp. 336.

9. Tenter AM, Heckeroth AR and Weiss LM (2000) Toxoplasma gondii: from animals to humans. International Journal for Parasitology 30, 1217-1259.

10. Nissapatorn V and Sawangiaroen $\mathbf{N}$ (2011) Parasitic infections in HIV infected individuals: diagnostic \& therapeutic challenges. Indian Journal of Medical Research 134, 878-897.

11. Tumash OL, Kozorez EI and Zhavoronok SV (2013) Toxoplasmosis among HIV-infected patients in the Gomel Region. Clinical Infectology and Parasitology 1, 51-59.

12. Correia CC, Melo HR and Costa VM (2010) Influence of neurotoxoplasmosis characteristics on real-time PCR sensitivity among AIDS patients in Brasil. Transactions of the Royal Society of Tropical Medicine and Hygiene 104, 24-28.

13. Saakyan SV et al. (2017) Specific immunoglobulins G and M in blood serum in retinoblastoma and pseudoretinoblastoma. Vestnik Oftalmologii 133, 12-16.

14. Ru W and Tang SJ (2017) HIV-associated synaptic degeneration. Molecular Brain 10, 40.

15. Gubareva EV et al. (2010) Features of epidemiology and diagnosis of toxoplasmosis in HIV infection. Zhurnal Mikrobiologii, Epidemiologii, $i$ Immunobiologii 2, 28-32.

16. Levine AJ et al. (2008) An exploratory study of long-term neurocognitive outcomes following recovery from opportunistic brain infections in HIV+ adults. Journal of Clinical and Experimental Neuropsychology 30, 836-843.
17. Zhao JR et al. (2010) Clinical analysis of 16 AIDS patients complicated with toxoplasmic encephalitis. Zhongguo Ji Sheng Chong Xue Yu Ji Sheng Chong Bing Za Zhi 30, 237-238.

18. Eggers C et al. (2017) HIV-1-associated neurocognitive disorder: epidemiology, pathogenesis, diagnosis, and treatment. Journal of Neurology 264, 1715-1727.

19. Romara $\mathbf{N}$ et al. (2001) White matter abnormalities in HIV-1 infection: a diffusion tensor imaging. Psychiatry Research 106, 15-24.

20. Arama V et al. (2014) Clinical relevance of the plasma load of cytomegalovirus in patients infected with HIV - a survival analysis. Journal of Medical Virology 86, 1821-1827.

21. Zinzerling VA (2014) Lesions of the central nervous system in HIV infection. HIV Infection and Immunosuppression 1, 40-45.

22. Trofimova TN, Belyakov NA and Rassokhin VV (2017) Radiology and HIV Infection. St. Petersburg: Baltic Medical Education Center, pp. 352.

23. Azovtseva OV et al. (2019) Clinical and pathomorphological manifestations of brain damage in HIV infection. HIV Infection and Immunosuppression 11, 37-48.

24. Essa MM, Song BJ and Chang SL (2019) Binge alcohol and HIV: leaky gut and neurodegeneration through the gut-brain axis. International Journal of Nutrition, Pharmacology, Neurological Diseases 9, 1-3.

25. Duarte SBL et al. (2017) Magnetic resonance imaging findings in central nervous system cryptococcosis: comparison between immunocompetent and immunocompromised patients. Radiologia Brasileira 50, 359-365.

26. da Silva FC et al. (2019) Agreement between diagnostic imaging methods for the evaluation of lymphadenopathies in HIV-infected/AIDS patients. Radiologia Brasileira 52, 7-11.

27. Hategan A et al. (2017) HIV Tat protein and amyloid- $\beta$ peptide form multifibrillar structures that cause neurotoxicity. Nature Structural \& Molecular Biology 24, 379-386.

28. Dean O et al. (2020) Brain magnetic resonance imaging findings associated with cognitive impairment in children and adolescents with human immunodeficiency virus in Zambia. Pediatric Neurology 102, $28-35$. 